\title{
Classification of non-Q-wave myocardial infarction according to electrocardiographic changes
}

\author{
HISAO OGAWA, KATSUHIKO HIRAMORI, KAZUO HAZE, MUNEYASU SAITO, \\ TETSUYA SUMIYOSHI, KENICHI FUKAMI, YOICHI GOTO, MASAO IKEDA
}

From the Division of Cardiology, Department of Medicine, National Cardiovascular Centre, Osaka, fapan

SUMMARY The characteristics of 93 patients in whom electrocardiographic recordings were obtained within 12 hours of the onset of non-Q-wave myocardial infarction were studied. Patients were divided into the three groups according to what electrocardiographic changes were seen. Forty nine patients had ST segment depression, 35 had ST segment elevation, and nine had T wave changes. Patients with ST segment depression had a higher rate of pump failure and multivessel disease than the other two groups. There were no significant differences in peak serum creatine kinase activity among the three groups. Twelve of 13 patients who died of non-Q-wave myocardial infarction in hospital had ST segment depression. Furthermore nine of them had attacks of non-Q-wave myocardial infarction with severe ST segment depression in many leads. At necropsy five of six patients who had shown severe ST segment depressions in many leads at the onset of non-Q-wave myocardial infarction were found to have circumferential subendocardial lesions with triple vessel disease.

This study suggests there are electrocardiographic subtypes of non-Q-wave myocardial infarction that are associated with specific patient characteristics.

Acute myocardial infarction has been divided into transmural myocardial infarction and nontransmural myocardial infarction on the basis of the development of abnormal $Q$ waves. Several previous studies comparing the characteristics of patients with non-transmural myocardial infarction and transmural myocardial infarction have reported conflicting results. Although some studies reported a lower hospital mortality in patients with nontransmural myocardial infarction than in those with transmural infarction. ${ }^{12}$ in others no significant differences were seen between the two groups. ${ }^{3-5}$ This may be because several clinical subtypes are included in the category non-transmural myocardial infarction. Few attempts have been made to identify these subtypes. ${ }^{6-8}$ Equally important is the inability to distinguish between non-transmural and transmural myocardial infarctions on the basis of abnormal $\mathrm{Q}$ waves alone. ${ }^{9}$ It is more accurate to use the terms $Q$ wave infarctions and non- $Q$-wave infarctions. ${ }^{9}$

Requests for reprints to Dr H Ogawa, Division of Cardiology, Kumamoto University School of Medicine, Honjo 1-1-1, Kumamoto City, Japan $\mathbf{8 6 0}$.

Accepted for publication 16 July 1985
We have investigated the characteristics of subtypes of non-Q-wave myocardial infarction. These subtypes were classified into three groups according to the electrocardiographic changes seen at the onset of infarction.

\section{Patients and methods}

Patients-Four hundred and seventy seven consecutive patients were admitted to the coronary care unit at the National Cardiovascular Centre Hospital between October 1977 and June 1982 with suspected acute myocardial infarction. Those who fulfilled the three criteria for diagnosis of non-Qwave myocardial infarction and from whom electrocardiograms had been obtained within 12 hours of the onset of acute myocardial infarction were included in this study. The criteria for diagnosis were (a) chest pain compatible with acute myocardial infarction, (b) peak serum creatine kinase activity which was at least twice the upper limit of normal, and $(c)$ persistent $S T$ segment changes, persistent $T$ wave changes, and absence of new abnormal $Q$ waves (that is $Q$ waves lasting more than $0.04 \mathrm{sec}-$ onds and with an amplitude which was more than $25 \%$ of the subsequent $R$ waves). In addition to cri- 


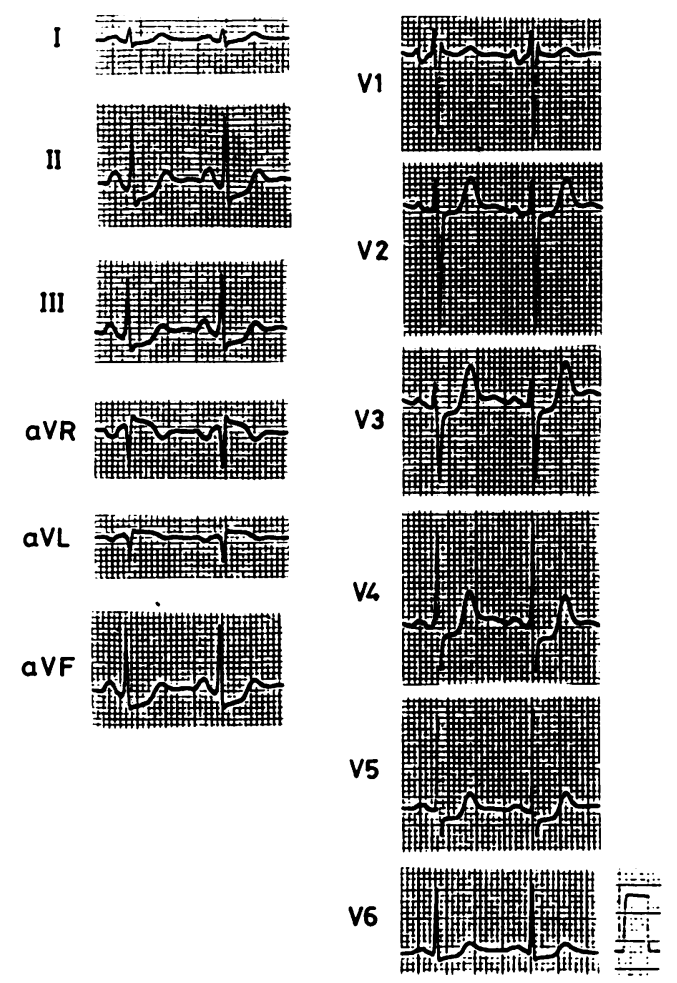

Fig. 1 Electrocardiogram in a 71 year old man showing $S T$ depression in leads II, III, aVF, and V3-V6. This patient was in Killip class I and peak serum creatine kinase activity was $1356 \mathrm{IU} / \mathrm{l}$.

teria $(a)$ and $(b)$ the diagnosis of $Q$ wave myocardial infarction required the development of abnormal $Q$ waves. In the case of posterior infarction, the development of initial $R$ waves in leads V1 and V2 of 0.04 seconds' duration with a $R / S$ ratio greater than 1 is considered to be as important as the development of an abnormal $Q$ wave. Ninety three patients with non-Q-wave myocardial infarction fulfilled all these criteria.

Electrocardiogram and serum creatine kinase activity were measured every three hours from the onset of infarction for 24 hours and every six hours from the onset of infarction for the next two days. There were three types of electrocardiographic findings associated with non-Q-wave myocardial infarction: $(a)$ onset with ST segment depression (Fig. 1); (b) onset with ST segment elevation (Fig. 2), and (c) onset with $T$ wave changes and without important ST segment changes (Fig. 3). We defined a finding of ST segment elevation in some leads and ST segment depression in other leads as ST elevation.

Cardiac catheterisation-As a rule hospital sur- vivors aged $\leqslant 65$ years with non-Q-wave myocardial infarction had coronary angiography about 4 weeks after the acute event. In some cases coronary angiography was also performed at necropsy. Coronary stenosis was regarded as important when a reduction of more than $75 \%$ of the luminal diameter was demonstrated in a major artery.

Statistical analysis-The results were analysed by the $\chi^{2}$ test and Student's $t$ test.

\section{Results}

Of the 93 patients with non-Q-wave myocardial infarction in whom electrocardiographic recordings were obtained within 12 hours of onset, 49 had ST depression, 35 had ST elevation, and nine had T wave changes (Fig. 4a).

The average (SD) age of patients was similar in these three groups (ST depression $63.4(10 \cdot 2)$, ST elevation $58.9(9 \cdot 1)$, $T$ wave changes $63.8(9 \cdot 1)$. Men comprised $76 \%$ of patients with ST depression, $80 \%$ of those with ST elevation, and $78 \%$ of those with $\mathrm{T}$ wave changes.

The patients were classified by Killip grade. ${ }^{10}$ Of those with ST depression, 28 (57\%) were in Killip class I, 11 in class II, four in class III, and six in class IV. Of those patients with ST elevation, 30 $(86 \%)$ were in class I, two in class II, two in class III, and one in class IV. All nine patients with T changes were in Killip class I. Thus, pump failure was significantly more common in patients with ST depression than those with the other two types of electrocardiographic change $(p<0.01)$ (Fig. $4 b)$.

Angiographic findings-Coronary angiography (including nine post mortem angiograms) was performed in 51 patients. The results were classified into four groups: patients without significant stenosis (group A), single vessel disease (group B), double vessel disease (group $C$ ), and triple vessel disease (group D). (Left main coronary artery disease was defined as double vessel disease.) Of the patients with ST depression, one was in group $A$, one in group $B$, three in group $C$, and 20 in group D. In contrast, of the patients with ST elevation, one was in group A, six in group B, eight in group C, and seven in group $D$. In those with $T$ changes, two were in group B and two in group C. Thus, multivessel (double or triple vessel) disease was significantly more common in patients with ST depression than in those with ST elevation or T wave changes $(92 \%$ vs $68 \%$ and $50 \%$ respectively, $\mathrm{p}<0.05$ ). There was triple vessel disease in $80 \%$ of the patients with ST depression (Fig. 4c).

Peak serum creatine kinase activity was measured in 81 patients. Forty patients had ST depression, 33 patients had ST elevation, and eight patients had T 


\section{$5 \mathrm{~h}$ after onset}

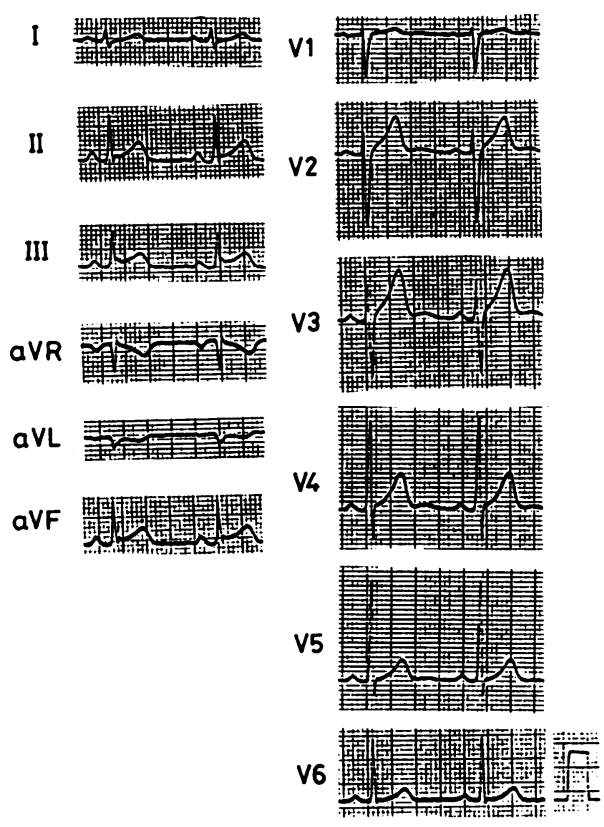

$7.5 \mathrm{~h}$ after onset
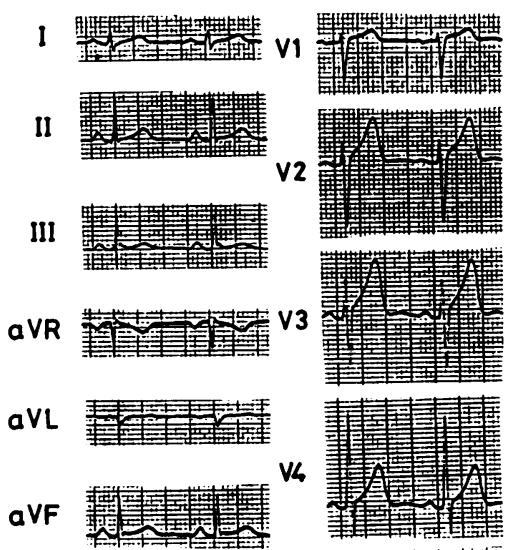

V5

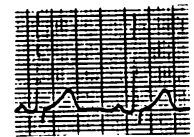

V6

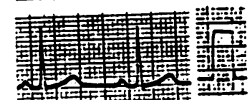

Fig. 2 Electrocardiogram in a man of 47 showing ST elevation in leads II, III, and aVF 5 hours after the onset of infarction. ST elevation resolved 7.5 hours after the onset of myocardial infarction. This patient was in Killip class I and had peak serum creatine kinase activity of $740 \mathrm{IU} / \mathrm{l}$.

Before AMI
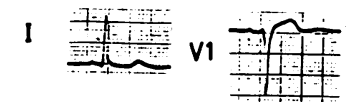

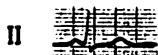

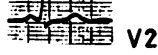

III

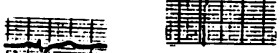

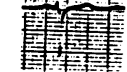

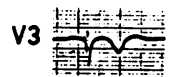

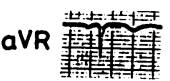

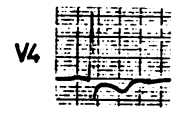

aVL

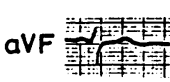
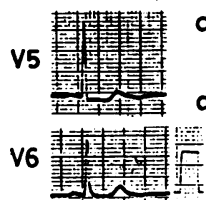

$2.5 \mathrm{~h}$ after onset

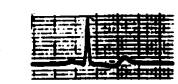

II

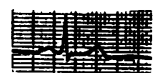

II

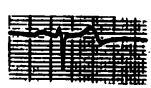

aVR

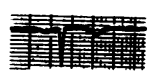

aVL

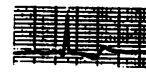

aVF

vi

V2

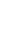

V3

V4
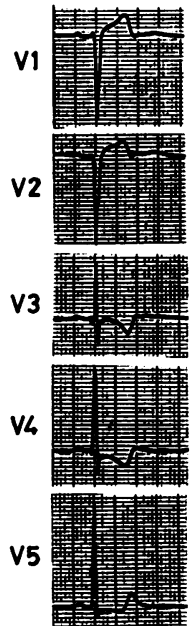

V6

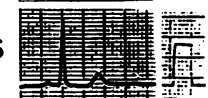

2 days after onset

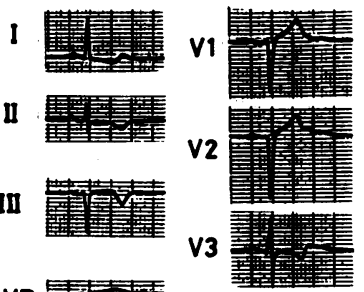

aVR

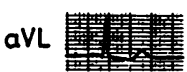

V4

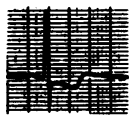

aVF 峦漬

V5

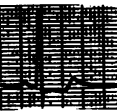

V6

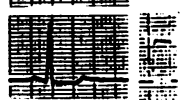

Fig. 3 Electrocardiogram in a man of 61 showing $T$ wave changes in lead III 2.5 hours after the onset of myocardial infarction. A negative T wave later appeared in leads II, III, and aVF. This patient was in Killip class I and had peak serum creatine kinase activity of $500 \mathrm{IU} / \mathrm{l}$. 

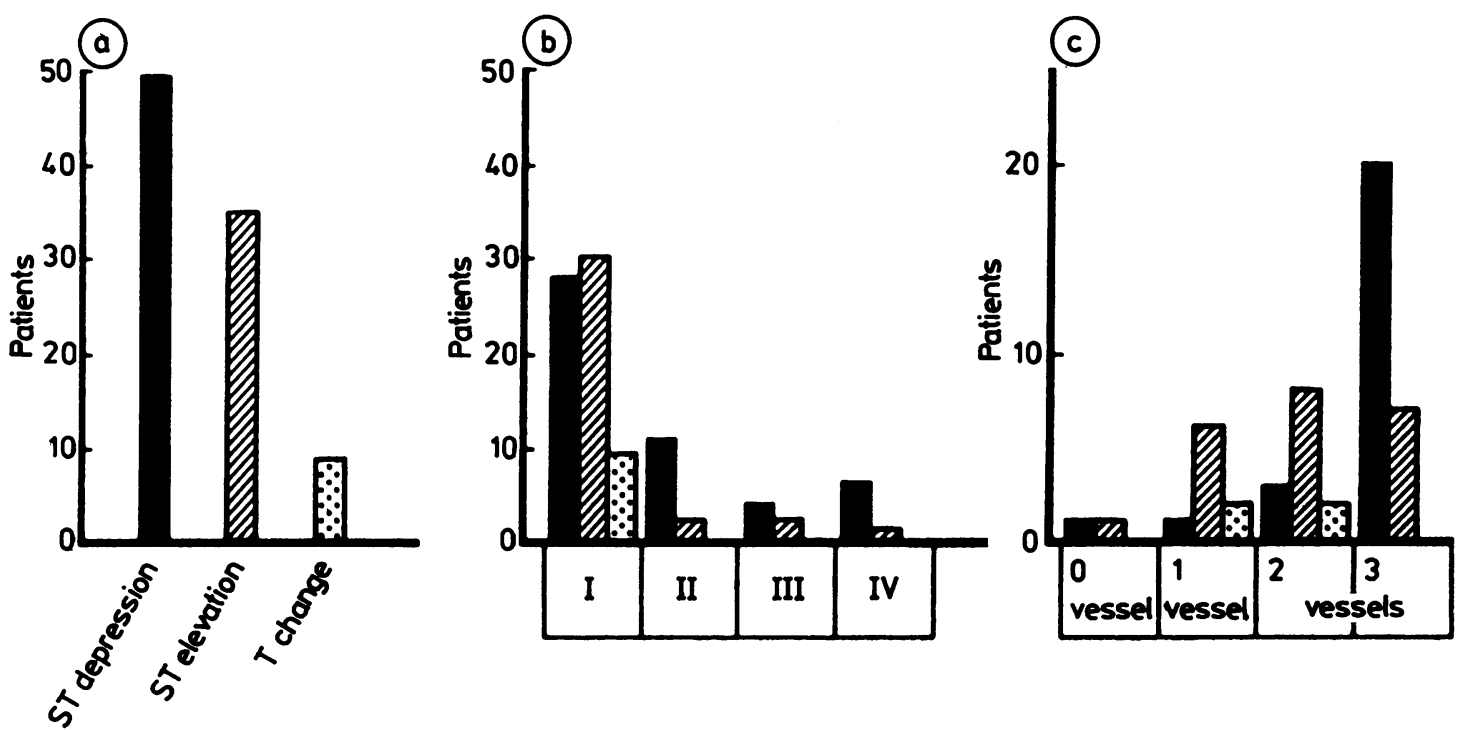

Fig. 4 Classification of non-Q-wave myocardial infarction by (a) electrocardiographic changes at onset, (b) Killip classification, and (c) number of significantly stenosed vessels ( $\geqslant 75 \%$ stenosis) in patients with the three types of electrocardiographic abnormality found in non-Q-wave myocardial infarction.

wave changes. Mean (SD) peak creatine kinase activity was 1420 (1197) IU/1 in patients with ST depression, 1317 (1134) IU/1 in those with ST elevation, and 777 (265) IU/1 in those with T wave changes. None of these differences was statistically significant (Table).

Death-Thirteen patients died of non-Q-wave myocardial infarction in hospital. The cause of death was left ventricular failure in 12 patients and arrhythmia in one. Twelve patients had ST depression and one had ST elevation. No patient with $\mathrm{T}$ wave changes died. Thus, death while in hospital was significantly more common in patients with ST depression than in patients with ST elevation or $\mathrm{T}$ wave changes $(24 \%$ vs $3 \%$ and $0 \%$ respectively, $\mathrm{p}<0.01$ ) (Table). Furthermore nine of the $12 \mathrm{pa}-$ tients with ST depression who died had pronounced and extensive ST segment depression at the onset of non-Q-wave myocardial infarction (that is ST segment depression $\geqslant 0.2 \mathrm{mV}$ in at least one lead and definite ST segment depression in more than five of the standard 12 leads). Necropsy in six of these nine patients showed that five of them had large subendocardial infarctions which were circumferential or nearly circumferential in extent. Angiography was performed post mortem on four of these five cases, and all four cases had triple vessel disease.

\section{Discussion}

The terms transmural myocardial infarction and non-transmural myocardial infarction have been used for many years in the electrocardiographic classification of acute myocardial infarction and they continue to be used despite evidence that the correlation with pathological findings is poor. ${ }^{9}$ Because acute myocardial infarction without abnormal $Q$ waves may or may not be seen in association with transmural infarction at necropsy, we prefer to use the terms " $Q$ wave myocardial infarction" and "non-Q-wave myocardial infarction".

The diagnosis of non- $\mathrm{Q}$-wave myocardial in-

Table Peak serum activities of creatine kinase (mean $(S D)$ ) and deaths in three types of non- $Q$-wave myocardial infarction

\begin{tabular}{lcccc}
\hline & $S T$ depression & ST elevation & $T$ wave change & Significance \\
\hline Cases & 49 & 35 & 9 \\
Peak creatine kinase (IU/1) & $1420(1197)(\mathrm{n}=40)$ & $1317(1134)(\mathrm{n}=33)$ & $\begin{array}{c}777(265)(\mathrm{n}=8) \\
0(0 \%)\end{array}$ & $\begin{array}{l}\text { NS } \\
\text { Deaths }\end{array}$ \\
\hline
\end{tabular}

NS, not significant. 
farction is generally based on a triad of features: chest pain compatible with acute myocardial infarction, an abnormal increase in peak serum activity of cardiac enzymes, and an abnormal electrocardiogram. We defined abnormal peak serum creatine kinase at being at least twice the upper limit of normal activity. Almost all our patients had increases in creatine kinase $\mathrm{MB}$, aspartate aminotransferase, and lactate dehydrogenase activity. The diagnosis of $Q$ wave myocardial infarction depends not only on the presence of the first two criteria but also on the development of abnormal $Q$ waves. ${ }^{11-13}$ Many believe that acute myocardial infarction without abnormal $Q$ waves can be distinguished clinically from infarction in which $Q$ waves are normal. ${ }^{2-4}$

The frequency of left ventricular failure in nonQ-wave myocardial infarction is generally believed to be less than that in $Q$ wave myocardial infarction. ${ }^{51214}$ This may be partly due to the size as well as the location of the infarction, since levels of serum enzyme activity are generally higher in patients with $Q$ wave infarction than in those with non$Q$-wave infarction. ${ }^{1515}$ In some patients, however, non-Q-wave myocardial infarction is complicated by severe left ventricular failure or cardiogenic shock. ${ }^{135}$ There may be clinical subtypes of non-Qwave myocardial infarction, but there have been few reports identifying such subtypes. ${ }^{36}$ We classified patients with non-Q-wave myocardial infarction into three groups according to the electrocardiographic changes seen at the onset of infarction. Left ventricular failure $(43 \%)$ and multivessel (double or triple vessel) disease $(92 \%)$, and hospital mortality $(24 \%$ ) were more frequent in those with ST depression than in those with ST elevation or $T$ wave changes. Twelve of 13 patients who died had ST depression. Peak creatine kinase activity in the serum, which is said to be associated with infarct size, ${ }^{1516}$ was not significantly different in the three electrocardiographic groups. This was thought to be because the ST depression groups included non-Q-wave myocardial infarctions of various sizes. We examined in more detail the electrocardiographic changes of patients who died. Nine of the 12 patients with ST depression who died had severe and extensive ST segment depression at the onset of non-Q-wave myocardial infarctionthat is ST segment depression $\geqslant 0.2 \mathrm{mV}$ in at least one lead and definite ST segment depression in more than 5 of the standard 12 leads. Necropsies done in six of these 9 patients showed that five of them had large subendocardial infarctions which were circumferential or nearly circumferential in extent.

It is difficult to explain the mechanism of ST seg- ment elevation at the onset of non-Q-wave myocardial infarction. One cause of ST segment elevation is coronary artery spasm, which could have initiated acute myocardial infarction in these patients. ${ }^{17-19} \mathrm{~T}$ wave inversion often occurred when the ST depression or elevation of the acute phase had resolved. The shortest duration of ST elevation was 2 hours and that of ST depression was 4 hours.

Our classification of non-Q-wave myocardial infarction according to the electrocardiographic changes seen at the onset of infarction is a useful indicator of outcome in the acute phase.

We thank Professor Hirofumi Yasue, Kumamoto University School of Medicine, and Professor David H Spodick, University of Massachusetts Medical School, for their helpful criticisms of this paper.

\section{References}

1 Thanavaro S, Krone RJ, Kleiger RE, et al. In-hospital prognosis of patients with first nontransmural and transmural infarctions. Circulation 1980; 61: 29-33.

2 Szklo M, Goldberg R, Kennedy HL, Tonascia JA. Survival of patients with nontransmural myocardial infarction: a population-based study. Am $\mathcal{F}$ Cardiol 1978; 42: 648-52.

3 Rigo P, Murray M, Taylor DR, Weisfeldt ML, Strauss HW, Pitt B. Hemodynamic and prognostic findings in patients with transmural and nontransmural infarction. Circulation 1975; 51: 1064-70.

4 Cannom DS, Levy W, Cohen LS. The short- and longterm prognosis of patients with transmural and nontransmural myocardial infarction. Am $\mathcal{F}$ Med 1976; 61: 452-8.

5 Madias JE, Chahine RA, Gorlin R, Blacklow DJ. A comparison of transmural and nontransmural acute myocardial infarction. Circulation 1974; 49: 498-507.

6 Lown B, Vassaux C, Hood WB Jr, Fakhro AM, Kaplinsky E, Roberge G. Unresolved problems in coronary care. Am $\mathcal{F}$ Cardiol 1967; 20: 494-508.

7 Cook RW, Edwards JE, Pruitt RD. Electrocardiographic changes in acute subendocardial infarction. I. Large subendocardial and large nontransmural infarcts. Circulation 1958; 18: 603-12.

8 Cook RW, Edwards JE, Pruitt RD. Electrocardiographic changes in acute subendocardial infarction. II. Small subendocardial infarcts. Circulation 1958; 18: 613-22.

9 Spodick DH. Q-wave infarction versus $S-T$ infarction: nonspecificity of electrocardiographic criteria for differentiating transmural and nontransmural lesions. Am f Cardiol 1983; 51: 913-5.

10 Killip T, Kimball JT. Treatment of myocardial infarction in a coronary care unit: a two year experience with 250 patients. Am $\mathcal{F}$ Cardiol 1967; 20: 457-64.

11 Schultze RA Jr, Pitt B, Griffith LSC, et al. Coronary angiography and left ventriculography in survivors of 
transmural and nontransmural myocardial infarction. Am $\mathcal{f}$ Med 1978; 64: 108-13.

12 Hutter AM Jr, DeSanctis RW, Flynn T, Yeatman LA. Non-transmural myocardial infarction: a comparison of hospital and late clinical course of patients with that of matched patients with transmural anterior and transmural inferior myocardial infarction. Am $\mathcal{f}$ Cardiol 1981; 48: 595-602.

13 Fabricius-Bjerre N, Munkvad M, Knudsen JB. Subendocardial and transmural myocardial infarction: a five year survival study. Am $\mathcal{F}$ Med 1979; 66: 986-90.

14 Madigan NP, Rutherford BD, Frye RL. The clinical course, early prognosis and coronary anatomy of subendocardial infarction. $A m$ f Med 1976; 60: 634-41.

15 Sobel BE, Shell WE. Serum enzyme determinations in the diagnosis and assessment of myocardial infarction. Circulation 1972; 45: 471-82.

16 Thompson PL, Fletcher EE, Katavatis V. Enzymatic indices of myocardial necrosis: influence on short- and long-term prognosis after myocardial infarction. Circulation 1979; 59: 113-9.

17 Oliva PB, Breckinridge JC. Arteriographic evidence of coronary arterial spasm in acute myocardial infarction. Circulation 1977; 56: 366-74.

18 Maseri A, L'Abbate A, Baroldi G, et al. Coronary vasospasm as a possible cause of myocardial infarction. $N$ Engl f Med 1978; 299: 1271-7.

19 Omote S, Yasue H, Takizawa A, et al. Coronary arteriographic findings during early hours of acute myocardial infarction: response to intracoronary injection of nitrates. Angiology 1983; 34: 553-60. 